\title{
Editorial
}

\section{Empirical methods in the study of maritime economics}

Maritime Economics \& Logistics (2017) 19, 189-195. doi:10.1057/s41278-016-0057-1; published online 4 January 2017

For more than two decades, the annual gathering of the International Association of Maritime Economists (IAME) has been the event around the globe where the latest developments in maritime research are first presented. In a very similar fashion, the meeting held in 2014 (15-18 July) in Norfolk Virginia, US, offered another opportunity to further the study of global economies and the maritime sector.

The conference on the theme "Maritime Economics in a Post-Expansion Panama Canal Era” was hosted by Old Dominion University and attracted government and industry leaders as well as maritime economists and researchers with an interest in shipping, ports, transport logistics, and trade. Scholars from around the globe discussed the prospects of the maritime world, in the face of changes and challenges that are shaping seaborne trade and maritime logistics worldwide.

The present special issue of Maritime Economics and Logistics presents five of the very best papers that were first presented at IAME 2014 and advance our knowledge on the application of empirical methods in the study of maritime economics.

The selected papers address specific thematic areas within a broad research field characterised by the use of various and diverse empirical methods. The research strands explored are of both scholarly and empirical importance. The intensity of competition and the contextual implementation of innovative technological and ICT solutions drives shipowners and port companies to exploit large databases of information for improving their performance and service quality. The application of statistical and operations research tools has the potential of enabling managers to identify critical pieces of information in the data collected and react to market changes. The use of advanced empirical methods on an increasingly large amount of data also allows academics to achieve more soundscientific outcomes.

Since their selection by the editors, the five studies have been extensively revised and as the peer review process concluded they offer useful insights of both scientific and practical-managerial value.

(c) 2016 Macmillan Publishers Ltd. 1479-2931 Maritime Economics \& Logistics Vol. 19, 2, 189-195 
The first two papers deal with the growing financialization of the shipping industry. The 2008 financial crisis provoked a dramatic industry turnaround, forcing various actors to reassess their perceptions on risk. The explosion of the financial bubble constituted a strong 'wake-up call' in terms of falling demand and risk rediscovering (Rodrigue et al, 2011). To mitigate such unprecedented risk in bulk and liner shipping, shipowners increased their recourse to financial derivatives, thus hedging freight rate variations, bunker costs and interest rate fluctuations. Financial derivatives are associated to a number of indexes (e.g. Baltic Dry Index and Shanghai Containerized Freight Index) that are daily updated, gathering large amounts of market information from various geographic areas. A suitable reading and usage of such indexes by maritime logistics companies has become a precondition for understanding industry changes and matching demand needs more appropriately (Kavussanos and Visvikis, 2004). For this purpose, powerful analytical tools are growingly implemented, to support entrepreneurial decisions and minimise risks. Next to this, maritime economists and other scholars are engaged in in-depth studies on the financial impact of shipowners' strategies, performing sophisticated analyses of derivatives (e.g. FFAs and freight futures), freight rates and financial-related matters.

In this context, the first paper of this volume by Ådland and Jia enhances our understanding of the effectiveness and the risks of hedging strategies in modern shipping. The study focuses on hedging risks, associated with in the Capesize freight markets. Nowadays, dry bulk operators hedge their freight market exposure on a fleet-wide basis, using longer-term contracts settled against global composite time charter rates. The authors argue that what matters for the performance of these hedges is not the short-term co-variation between spot and FFA prices, but rather the mismatch between the income stream of the physical fleet and the relevant spot rate index. Denoting the standard deviation of this earnings differential as the "physical basis risk," the study simulates, in a rather novel way, the average earnings of a fleet of Capesize vessels over the main trading routes. It does so by making use of conditional probabilities, based on known historical commodity flows. It is shown that physical basis risk is reduced (but does not disappear), i.e. the effectiveness of the hedge improves, when the fleet size is increasing; a result similar to a portfolio diversification effect.

The conclusions suggest that physical basis risk never disappears, even for a very large fleet, due to a moving-average effect in earnings. While increasing the fleet size lowers basis risk, this diversification effect is low beyond a relatively small fleet size of about ten ships. Not surprisingly, the study demonstrates that physical basis risk is greater for shorter hedging maturities.

By linking theoretical and empirical advances, this empirical paper offers more than a simple reminder to shipping investors that "big (diversified fleets) need not be better (in terms of earnings risks)". The results guide shipowners, charterers 
and operators that are actively hedging their freight market exposure, in the design of more efficient hedging strategies, in terms of contract duration and realised trading patterns, and suggests that the Baltic Exchange and its stakeholders engage in the continuous improvement of the quality of spot-rate indices.

The reduction of risks for stakeholders takes centre stage in the case of the second paper as well. Jason Angelopoulos examines the structures of Baltic Dry Index (BDI), providing a framework for capturing the frequency and periodicity variation of the index.

With the daily BDI having a rich spectral content, this study attempts to supplement the discussion on BDI's cyclical behaviour. Methodologically, the employment of time-frequency analysis facilitates assessing the existence of distinct cycles within both the low- and high-frequency bands of the BDI. The dynamic nature and actual patterns of BDI, as well as the caveats and challenges associated with the use of this index are illustrated in this contribution. The used trend removal or filtering process reveal that - apart from a long-term trend - a number of distinctive cycles of low, middle, or high frequencies are present, with most of them marked by different features and levels of prominence. The study also reveals the presence of a dominant, albeit temporally constrained cycle. Furthermore, the used representations reveal periods of fading of distinguishable high frequencies.

Beyond the paper's interpretation of trends over time, and the generation of knowledge of BDI trends that is useful to practitioners, this work contributes from a methodological point of view too. It introduces potential techniques for enhancing the footprint of BDI signal frequency shifts over time, whereas it provides foundations for exploring possible synergies between time-domain and time-frequency analysis.

Another dimension of the contemporary sectorial complexity in maritime and port logistics that stimulates academic research, supported by empirical methods, is the proliferation of intricate shipping service networks across the globe (Ducruet and Notteboom, 2012). Beyond its low profitability levels, liner shipping is today marked by the evolution of alliances, and seeking of economies of scale, two practices that result in the restructuring of shipping networks. The acceleration of alliance formation (see: Notteboom, 2015), implies cargo sharing and capacity adjustments achieved via the restructuring of existing networks. The seeking of economies of scale is reached mainly by deploying bigger vessels in a smaller number of ports of call, and a greater reliance on transshipment via the usage of multiple hub-and-spoke practices (cf. Rodrigue, 2015). The expansion of the Panama Canal - the theme of the Conference to which this present issue is devoted - favours further changes in port competition, as the setting of circum-equatorial deep-sea services with north/south connections, increases the dependence on transshipment (ibid.). In 
all different markets cargo throughput is not determined by captive hinterlands and land-based factors only, but is also an outcome of shipping networking and port choice, and this is evident all over the world (see: Wilmsmeier, 2014).

The third paper in this volume focuses on this issue. Dong-Joon Kang and SuHan Woo examine the not yet sufficiently identified relationship between the structures and characteristics of liner shipping networks and port cargo throughput. The authors employ network analysis, in order to evaluate network characteristics of ports, and panel regression analysis to investigate the relationship between port network characteristics and cargo throughput. Degree, closeness, betweenness, and eigenvector are the four centrality indices used to evaluate the network characteristics of ports, as they evolved between 2006 and 2011. The results suggest that liner shipping networks follow smallworld and scale-free characteristics; the latter indicating that these networks are concentrated on a small number of ports with high connectivity. Throughput performance is determined not only by macroeconomic variables and service capacities, but also by the centrality of ports.

The findings are useful for all involved in port planning and development whether these are port authorities, terminal operators, or national, regional or local decision-makers. Beyond other market and geography considerations, port planners and operators should also consider how their ports are positioned in shipping networks, how they can improve the roles their ports are playing in such networks and how they can alter them.

In addition, this study calls for novel academic research methods that can deliver more timely and regular updates, so as to conform to the dynamics of the industry. Despite the use of an extensive dataset - as the study explores maritime transport networks with longer and more consecutive time spans than in previous literature - there is no doubt that larger datasets with longer timeframes and more firms would increase the understanding of maritime transport networks. The investigation into liner shipping networks in specific regions, as well as comparative studies, also emerge as areas for further exploration.

The remaining of the volume turns to another highly interesting issue. Contextual instability and complexity have triggered logistics actors to resort to suitable forecasting techniques in shipping and port management. Academic literature recognises that appropriate models, capable of forecasting port throughput, are necessary tools to support long-term strategic decisions on the planning and upsizing of seaport terminals (Parola and Sciomachen, 2009), as terminal and yard capacity cannot easily be adjusted in the short run (Peng and $\mathrm{Chu}$, 2009). Forecasting tools provide both port operators and managing authorities with useful insights, for bringing a solid empirical foundation to executive decisions and investment strategies. Yet, identifying appropriate forecasting methods and tools has proved to be a major challenge (Pallis et al, 
2011). Analogous considerations can be drawn for shipowners who need empirical support for taking more inspired decisions on capacity allocation across various routes in the short/mid-term. More importantly, as regards growth strategies implying investments in new vessels, the estimation of longterm demand trends is a key factor that can reduce the risk of decisional bias by shipowners (Scarsi, 2007).

Forecasting container volumes in liner shipping markets is the theme of the last two studies of the present special issue. Each of these studies is based on different assumptions, and endorses different perspectives and methodologies. They both provide some new perspectives, taking into account modern structures of container shipping. While they do not answer in a firm way the forecasting problem - the authors include in their respective manuscripts references to existing limitations - they go beyond conventional forecasting techniques (i.e. those based on historical data) and contribute methodologically with novel approaches to the estimation of the implications of maritime trade developments.

Ryuichi Shibasaki, Iijima Takayuki, Taiji Kawakami, Kadono Takashi and Shishido Tatsuyuki develop a model that utilises shippers' perspectives and the structures of both maritime and landside intermodal shipping networks, in an attempt to predict worldwide container movements. The model focuses on the response of shippers to changes in the levels of service of liner shipping companies and ports, treating carrier' decisions, as regards the level of services and ports of call, as exogenous variables. The focus is on network building, rather than the actual costs of shipping services.

The authors apply their model to Central America, as a proxy for future geographically broader applications. This is a region consisting of several linershipping networks, which differ depending on the coastline the port is situated at, where international maritime containers are often transported across national borders by land. The empirical findings reproduce well the actual container movements, in terms of container cargo throughput per port, land container flows, and maritime flows per shipping company. Following the sensitivity to key model parameters, the authors conclude that the proposed model can predict the volume of containers handled in the ports, subject to a given liner-shipping network.

This ambitious effort is a timely contribution, as the discussion on the formation of liner shipping networks is largely linked with the connectivity of maritime transportation legs with the associated hinterland networks, and their embeddedness in supply chains. As ports compete in gaining calls, the prediction of volumes offers a useful insight for all stakeholders.

The study provides a research path that is complementary to research examining optimal shipping networks, or optimal levels of services from a carriers' perspective. It also complements studies focusing on ship routing and scheduling models. However, the validity of the model should be carefully and 
continuously examined by further sensitivity analyses and other means. Applications of the developed model to other regions of the world would extend the model beyond a case-study.

The final paper also focuses on the forecasting of container volumes in a port, this time concentrating on the implications on port development. Sang-Yoon Lee, Hyunwoo Lim and Hwa-Joong Kim explore a practical method for forecasting potential container cargo volumes via a port development project - such as dredging - hat can be used to evaluate the economic feasibility of such projects.

Methodologically, the authors' effort is commendable as they attempt to go beyond the conventional port throughput forecasting, which is typically performed by extrapolating historical trends that reflect anticipated economic growth for various projection periods. The authors combine port choice and an autoregressive integrated moving average (ARIMA) model. Their case study is the entrance channel improvement plan for Incheon New Port in South Korea. Based on stated preference data collected from domestic shippers, a discrete choice analysis is performed to estimate the future market share of three major ports in South Korea, namely Busan, Gwangyang, and Incheon. The estimated market share of Incheon New Port is used to forecast the port's future container volume, derived from the ARIMA model, and the potential port development scenarios.

Still, as the authors admit, forecasting the increase in port throughput, due to infrastructure enhancement, remains a major challenge for many different reasons, i.e. lack of historical data reflecting similar impacts on previous port developments; potential changes in the port choices of stakeholders; and the fact that port users may not necessarily perform as stated.

Besides, any conclusion on the impact of port development projects on port competition and competitiveness should always be considered taking into account a number of other developments that take place in conjunction with them. As it has well been established the ways that port performance, strategies (Brooks and Pallis, 2013) and pricing practices (Haralambides, 2015) unfold have also a major impact on attracting shippers and ocean carriers - and are thus worth of further research.

\section{References}

Brooks, M.R. and Pallis, A.A. (2013) Advances in port performance and strategy. Research in Transportation Business and Management 8: 1-6.

Ducruet, C. and Notteboom, T. (2012) The worldwide maritime network of container shipping: spatial structure and regional dynamics. Global Networks 12(3): 395-423.

Haralambides H.E. (2015) Competition, excess capacity and the pricing of port infrastructure. In: Idem (ed.) Port Management. London, UK: Palgrave 221-252.

Kavussanos, M.G. and Visvikis, I.D. (2004) Market interactions in returns and volatilities between spot and forward shipping freight markets. Journal of Banking \& Finance 28(8): 2015-2049. 
Notteboom, T. (2015) Alliances in container shipping: searching for the best dance partners, Article published at http://www.Porteconomic.eu/, assessed 10 April 2016.

Pallis A.A., Vitsounis T.K., De Langen P.W. and Notteboom T.E. (2011) Port economics, policy and management: Content classification and survey. Transport Reviews 31(4): 445-471.

Parola, F. and Sciomachen, A. (2009) Modal split evaluation of a maritime container terminal. Maritime Economics and Logistics 11(1): 77-97.

Peng, W.Y. and Chu, C.W. (2009) A comparison of univariate methods for forecasting container throughput volumes. Mathematical and Computer Modelling 50(7): 1045-1057.

Rodrigue, J.-P. (2015) Transshipment hubs: connecting global and regional maritime shipping networks, Article published at http://www.Porteconomic.eu/, assessed 10 April 2016.

Rodrigue, J.P., Notteboom, T. and Pallis, A.A. (2011) The financialization of the port and terminal industry: revisiting risk and embeddedness. Maritime Policy and Management 38(2): 191-213.

Scarsi, R. (2007) The bulk shipping business: market cycles and shipowners' biases. Maritime Policy and Management 34(6): 577-590.

Wilmsmeier G. (2014) Liner shipping markets, networks and strategies - The implications for port development on the West Coast of South America: The case of Chile. OECD/ITF Discussion Paper No. 2013-22. Paris: OECD.

Athanasios A. Pallis

University of the Aegean, Chios, Greece.

E-mail: apallis@aegean.gr

Francesco Parola

University of Genova, Genoa, Italy. E-mail:parola@economia.unige.it

Michele Acciaro

Kühne Logistics University (KLU), Hamburg, Germany. E-mail: Acciaro@the-klu.org 